\title{
ORIGINAL ARTICLE \\ Electroacupuncture at Zusanli (ST36) ameliorates colonic neuronal nitric oxide synthase upregulation in rats with neurogenic bowel dysfunction following spinal cord injury
}

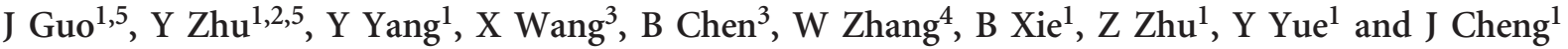

Study design Experimental study.

Objective To determine the effects of electroacupuncture (EA) at Zusanli (ST36) on colonic motility and neuronal nitric oxide synthase (nNOS) expression in rats with neurogenic bowel dysfunction (NBD) after spinal cord injury (SCI).

Setting Second School of Clinical Medical, Nanjing University of Chinese Medicine, Jiangsu, China.

Methods We divided 30 adult Sprague-Dawley rats into a sham group (10 rats), a model group (SCl alone, 10 rats) and a EA group (SCI+EA at ST36, 10 rats). Defecation time was recorded as the time from activated carbon administration (on day 15) to evacuation of the first black stool. Immunohistochemical, real-time PCR and western blot analyses were performed to assess changes in nNOSimmunoreactive cells, and nNOS messenger RNA (mRNA) and protein, respectively, after 14 experimental days.

Results Defecation time was lower in the EA group than in the model group $(P<0.01)$. On immunohistochemical analysis, nNOS was localized in the myenteric plexus of the colon. The number of nNOS-immunoreactive cells and the intensity of nNOS staining were greater in the model group than in the sham group and lesser in the EA group than in the model group. Consistent with the immunohistochemical findings, nNOS mRNA and protein expression was higher in the model group than in the sham group and lower in the EA group than in the model group $(P<0.05$ for both).

Conclusion Increased colonic nNOS expression can induce/aggravate NBD in SCI rats. EA at ST36 ameliorated NBD, possibly by downregulating colonic nNOS expression.

Spinal Cord (2016) 54, 1139-1144; doi:10.1038/sc.2016.76; published online 5 July 2016

\section{INTRODUCTION}

A large majority of people with spinal cord injury (SCI)-induced neurogenic bowel dysfunction (NBD) suffer from functional intestinal obstruction, constipation, fecal incontinence or a combination of these conditions. ${ }^{1-3}$ In SCI patients with NBD, there is a slowdown of the basal electrical rhythm of the colon, delayed colonic motility and severe anorectal dysfunction. ${ }^{4,5} \mathrm{NBD}$ causes great physical and psychological harm to SCI patients and results in a poor healthrelated quality of life. ${ }^{1,6}$

Neurogenic bowel management after SCI includes non-pharmacological, pharmacological and surgical treatments. ${ }^{7}$ However, none of these treatments can help regain self-controlled bowel function in SCI patients. Moreover, some treatments such as catheterization, colostomy and enema will likely result in pain and adverse event. Electroacupuncture (EA) is a simple, noticeably effective and sideeffect-free management. The effects of EA in NBD have been supported by animal and clinical studies. Hong et al. ${ }^{8}$ demonstrated that EA at Zusanli (ST36) could improve the gastric-emptying rate and promote gastrointestinal motility in rats with SCI. In addition, Wong et al. ${ }^{9}$ found that EA could decrease the need with bowel care in patients with NBD after SCI. Liu et al. ${ }^{10}$ also reported that EA can improve SCI patients' self-controlled bowel functions. However, these studies had some weaknesses in trial methodology and reporting. As the quality of these acupuncture-based studies is of dispute, evidence regarding the effects of $\mathrm{EA}$ in NBD is still lacking. In addition, the mechanism of EA in NBD has yet to be clarified.

Colon motility is mediated by contractile cholinergic neurons and relaxant non-adrenergic non-cholinergic (NANC) neurons in the myenteric plexus between the circular and longitudinal muscle layers. Decreased or increased NANC neurons might be involved in the pathophysiology of NBD. Nitric oxide (NO) is the primary inhibitory NANC neurotransmitter, which is synthesized by the neuronal isoform of NO synthase (nNOS). The first article on the immunological detection of nNOS in rat myenteric neural cells and processes was reported in $1990 .{ }^{11}$ Since then, nNOS localization in myenteric neural cells and processes has been detected in different species including humans. ${ }^{12-14}$ In addition, research over the last few years has revealed that spinal cord hemisection, impact injury or focal spinal cord trauma results in the upregulation of nNOS expression. ${ }^{15,16}$ Thus, nNOS may participate in the pathogenesis of NBD after SCI.

${ }^{1}$ Second School of Clinical Medical, Nanjing University of Chinese Medicine, Nanjing, China; ${ }^{2}$ Centre of Physical Medicine and Rehabilitation, Hainan Provincial Nongken General Hospital, Hainan, China; ${ }^{3}$ Department of Sport Rehabilitation, Shanghai University of Sport, Shanghai, China and ${ }^{4}$ Department of Rehabilitation Medicine, Jiangsu Province Hospital, Nanjing, China

${ }^{5}$ These authors contributed equally to this work

Correspondence: Dr J Cheng, Second School of Clinical Medical, Nanjing University of Chinese Medicine, 138 Xianlin Road, Nanjing 210000, China.

E-mail: grace7612@126.com

Received 25 October 2015; revised 24 March 2016; accepted 25 March 2016; published online 5 July 2016 
From this background, we hypothesized that nNOS downregulation may constitute the mechanism underlying the effects of EA treatments on NBD. We performed immunohistochemical, real-time reverse transcription PCR (RT-qPCR) and western blot analyses to examine the changes in nNOS messenger RNA (mRNA) expression, nNOS protein level and nNOS immunoreactivity, respectively, in the myenteric plexus of the colon in rats subjected to SCI.

\section{MATERIALS AND METHODS}

\section{Animals and groups}

The experiments were approved by the Animal Care and Use Committee of Nanjing University of Chinese Medicine and were in accordance with international ethical guidelines for the care and use of laboratory animals. All efforts were made to minimize the number of animals used and their suffering. A total of 30 adult Sprague-Dawley rats, 15 males and 15 females, weighing $300 \pm 20$ g (SCXK 2008-0016, Shanghai Laboratory Animal Research Center, Shanghai, China) were used in this experiment. The rats were housed five per cage on a 12-h dark/light cycle in a temperature- and humidity-controlled environment. Food and water were supplied ad libitum before the experiment.

The animals were assigned randomly into two groups as follows: (1) sham group, animals subjected to sham SCI operation at Th10 $(n=10)$; (2) SCI model group, animals subjected to SCI $(n=20)$. Then, the SCI model that successfully established, in accordance with the random number table, was divided into the EA group (SCI+EA at ST36, $5 \mathrm{~mm}$ perpendicular needling; $2 \mathrm{~Hz} / 15 \mathrm{~Hz}, 1-2 \mathrm{~mA}$, condensation-rarefaction wave; $30 \mathrm{~min}$ per day) and the model group (SCI alone).

\section{SCI model}

The SCI was inflicted under anesthesia with $10 \%$ chloral hydrate administered via intraperitoneal (i.p.) injection $\left(300 \mathrm{mg} \mathrm{kg}^{-1}\right)$. Th11-Th12 laminectomies were performed with the dura intact. As shown in Figure 1, the spinal cord was exposed very carefully at a low thoracic level (Th10) and severely damaged using an NYU impactor (height, $60 \mathrm{~mm}$; weight, $10 \mathrm{~g}$; W.M. Keck Center for Collaborative Neuroscience, Rutgers, the State University of New Jersey, USA). ${ }^{17,18}$ Bleeding was observed from the impacted dura, and the lower limbs and tail of the rats appeared flaccid. The overlying muscle and skin were then sutured to close the wound. The rats were postoperatively treated with gentamicin (5000 $\mathrm{U} \mathrm{kg}^{-1}$ per day, i.p.) for 14 days. The control (sham group) rats underwent all the surgical procedures, except for the SCI. In these animals, Th11-Th12 laminectomies were performed, and the spinal cord was exposed for $5 \mathrm{~min}$, after which the muscle and skin incisions were closed. All the animals were housed individually in clear plastic cages and given food ad libitum. Water was supplied twice a day at the same time every day for 14 days, and $2 \mathrm{~h}$ later the bladders of the SCI rats were emptied by the Crede technique. In addition, the experimenters tried their best to keep the perineum and paralyzed lower limbs of the rats clean.

The SCI model was judged using the modified 21-Point Basso, Beattie, Bresnahan (BBB) Locomotor Rating Scale. BBB score was measured at the 2nd and 15th day after modeling, and 0 point at the 2nd day after modeling indicates success of the SCI model. The rats were individually assessed in an open space and independently observed by two researchers who were blinded to the study groups.

\section{EA protocol}

Needles $\left(0.25 \times 13 \mathrm{~mm}^{2}\right.$; Huatuo, Suzhou Medical Appliance, Suzhou, Jiangsu, China) and Electro-Acu Stimulators (SDZ-II; Suzhou Medical Appliance) were used in this study. The parameters of electric stimulation were as follows: condensation-rarefaction wave with an electric current frequency of 2 or $15 \mathrm{~Hz}$; and intensity between 1 and $2 \mathrm{~mA}$.

Acupoints were localized according to the WHO Standardized Acupuncture Points Location. Needles were bilaterally and vertically inserted at ST36 to a depth of $5 \mathrm{~mm}$. Paired alligator clips with negative and positive electrodes were attached to the needle holders at the right and left ST36. The rats in the EA group received EA treatment for $30 \mathrm{~min}$ per day for 14 days.

\section{Measurement of defecation time}

Ten rats in each group were used to examine intestinal peristaltic function. The rats were fasted for $24 \mathrm{~h}$ from the 14th day, but they were not deprived of water. After $24 \mathrm{~h}$, the rats in each group were orally administered $2 \mathrm{ml}$ of $10 \%$ activated carbon. We then recorded the time until the defecation of the first black stool.

\section{Immunohistochemistry}

Five rats were randomly selected from each group and deeply anesthetized with $10 \%$ chloral hydrate $\left(300 \mathrm{mg} \mathrm{kg}^{-1}\right.$, i.p.). Then, a $1-\mathrm{cm}$ length of the distal colon was obtained from each rat and fixed in $4 \%$ paraformaldehyde for histological examination. The tissues were embedded in paraffin and cut into 4- $\mu$ m-thick serial coronal sections on Leica RM 2135 BioCut Rotary Microtome (Leica Ltd., Wetzlar, Germany). Then, two to four colon sections per animal were obtained. After dewaxing and dehydration, the sections were incubated in $3 \% \mathrm{H}_{2} \mathrm{O}_{2}$ at room temperature for $10 \mathrm{~min}$ and then rinsed in distilled water. Next, the slides were placed in a pressure cooker filled with boiling sodium citrate buffer ( $\mathrm{pH} \mathrm{6.0)}$ and heated under pressure. At $1.5 \mathrm{~min}$ after steaming, the pressure cooker was removed from the heat source and cooled down to room temperature with tap water. The container was opened, the slides were rinsed twice for 2 min each with phosphate-buffered saline (PBS; pH 7.4), and then blocked with $5 \%$ bovine serum albumin for $20 \mathrm{~min}$ at room temperature. The serum was removed, and the primary antibody was added. After incubating the tissue at $37^{\circ} \mathrm{C}$ for $1.5 \mathrm{~h}$, we washed the sections three times with PBS for 2 min each and then incubated them with a secondary antibody at $37^{\circ} \mathrm{C}$ for $20 \mathrm{~min}$. After three 2-min rinses in PBS, the slides were incubated with streptavidin-biotin complex for $20 \mathrm{~min}$ at $37^{\circ} \mathrm{C}$. The sections were rinsed again in PBS for four times, for $5 \mathrm{~min}$ each, and then the staining was visualized using diaminobenzidine as the chromogen. The slides were observed and examined for color change in order to determine when to terminate chromogen development. Antibody staining was followed by counterstaining with hematoxylin for $1 \mathrm{~min}$. Finally, the sections were dehydrated, cleared and mounted with neutral balsam. Two slides per rat and four to five fields per slide were randomly selected and micrographed at $\times 200$. The average optical density was calculated by the JD801 Imaging Analysis System (JEDA Science-Technology Development Co., Jiangsu, China).
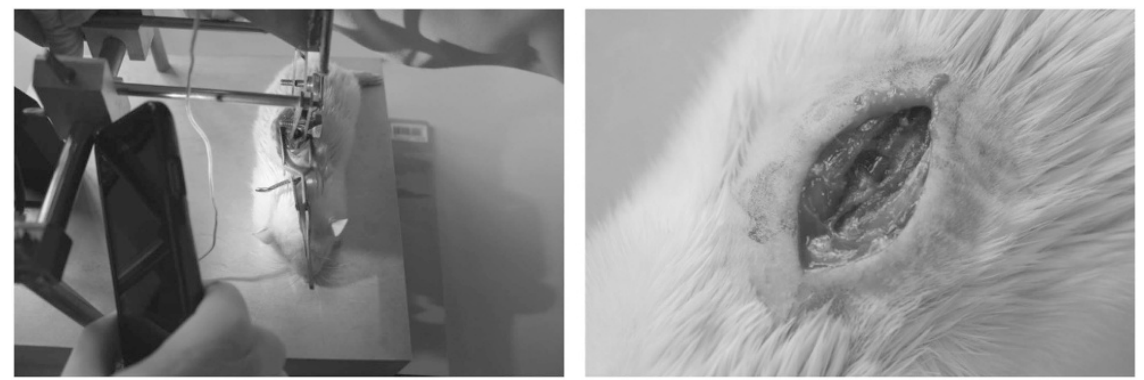

Figure 1 Establishment of the spinal cord injury model by the weight dropping method. A full color version of this figure is available at the Spinal Cord journal online. 


\section{Real-time PCR}

Five rats were randomly selected from each group for RT-qPCR assays of nNOS mRNA expression in the colon tissues. ${ }^{8}$ In brief, treated colon tissues were lysed, and total RNA was extracted using RNA Isolater Total RNA Extraction Reagent (R401-01, Vazyme Biotech, Nanjing, China). The total RNA $(2.5 \mu \mathrm{g})$ was reverse transcribed in $50 \mu \mathrm{l}$ of a reaction system using HiScript Q RT SuperMix for qPCR (R213, Vazyme Biotech). The thermal cycling parameters for the reverse transcription were $10 \mathrm{~min}$ at $25^{\circ} \mathrm{C}, 30 \mathrm{~min}$ at $42^{\circ} \mathrm{C}$ and $5 \mathrm{~min}$ at $85^{\circ} \mathrm{C}$ with subsequent cooling to $4{ }^{\circ} \mathrm{C}$. First-strand complementary DNA was generated as the template. Then, RT-qPCR of the complementary DNA was carried out using SYBR Green I, according to the manufacturer's protocols (Takara, Dalian, China). Glyceraldehyde 3-phosphate dehydrogenase was selected as the endogenous reference gene. The nNOS forward primer sequence was $5^{\prime}$-TGAACGGCTGGAGGATGC- ${ }^{\prime}$, whereas the reverse primer sequence was 5'-CAGGGTGGGAGGCGAGAT-3'. The glyceraldehyde 3-phosphate dehydrogenase forward primer sequence was $5^{\prime}$-GAGTCCACTGGCGTC TTCA-3', and its reverse primer sequence was 5'-GGGGTGCTAAGCA GTTGGT- $3^{\prime}$. Reactions were incubated at $95^{\circ} \mathrm{C}$ for $5 \mathrm{~min}$ followed by 40 cycles of $10 \mathrm{~s}$ at $95^{\circ} \mathrm{C}$ and $30 \mathrm{~s}$ at $60^{\circ} \mathrm{C}$. After amplification, PCR product bands were examined on a $2 \%$ electrophoretic agarose gel, and the specificity of each reaction was controlled by melting curve analysis. The relative level of mRNA was calculated using the equation $2^{-\Delta \Delta \mathrm{CT}}$, where $\Delta \Delta \mathrm{CT}=(\mathrm{CT}$ target gene $-\mathrm{CT}$ control gene $)$ sample2-(CT target gene $-\mathrm{CT}$ control gene $)$ samplel.

\section{Western blot analysis}

Four rats were randomly selected from each group for western blot analysis. Samples of the colon were homogenized with $1 \mathrm{ml}$ cold radioimmunoprecipitation assay lysis buffer containing $2 \mu \mathrm{l}$ protease inhibitor cocktail tablets (Vazyme Biotech). Manipulations were carried out on ice. Each sample $(100 \mathrm{mg}$ ) was mixed with $1 \mathrm{ml}$ lysis buffer and then centrifuged at $10,000 \times g$ at $4{ }^{\circ} \mathrm{C}$ for $5 \mathrm{~min}$. Protein concentrations of the supernatants were measured using the bicinchoninic acid method. Then, the samples were boiled at $100^{\circ} \mathrm{C}$ for $5 \mathrm{~min}$. Aliquots of $120 \mu \mathrm{g}$ of the crude samples were separated using SDS-polyacrylamide gel electrophoresis, and the proteins were electrophoretically transferred from the gel to polyvinylidene difluoride membranes. Unoccupied protein-binding sites on the membranes were blocked with $5 \%$ milk powder (non-fat dry milk) in PBS containing Tween-20 (PBS-T) for $2 \mathrm{~h}$ at room temperature, and the membranes were subsequently incubated overnight at $4{ }^{\circ} \mathrm{C}$ with primary antibodies recognizing tubulin (TRUE-ref anti-a-tubulin $\mathrm{mAb}$; dilution, 1:5000 in PBS-T; Vazyme Biotech) and nNOS (anti-nNOS; dilution, 1:500 in PBS-T; Abcam, Cambridge, UK). The blots were washed extensively in PBS-T after incubation with the primary antibodies and then exposed to the secondary antibodies, namely, horseradish peroxidaseconjugated goat anti-mouse IgG $(\mathrm{H}+\mathrm{L})$ and horseradish peroxidaseconjugated goat anti-rabbit IgG $(\mathrm{H}+\mathrm{L})$, at a dilution of 1:5000 in PBS-T, for $1 \mathrm{~h}$ at room temperature. Next, the blots were rinsed with PBS-T again, followed by color development using electrochemiluminescence (ECL) reagent. The immunoblots were scanned usingChemiScope3500 chemiluminescence imaging systems (ClinX Science Instruments, Shanghai, China), and the optical densities of the target protein bands were quantified using Chemi Analysis (Gel Analysis v2.02, NIH, Bethesda, MD, USA). The results were determined by the ratio of nNOS to tubulin. All of the assessments were measured by blinded observers.

\section{Statistical analysis}

All statistical calculations were performed using SPSS software (version 16.0, SPSS, Inc., Chicago, IL, USA). Intergroup comparisons were performed using one-way analysis of variance. If the variance is equal, we will use the least significant difference test. Otherwise, the Dunnett T3 test will be used. All values are reported as means \pm s.e. $P$ values $<0.05$ were considered statistically significant.

\section{RESULTS}

BBB scores at the 2nd and 15th day after SCI modeling

The BBB scores on the 2nd day after the operations showed that the SCI model had been successfully established in all 20 rats subjected to
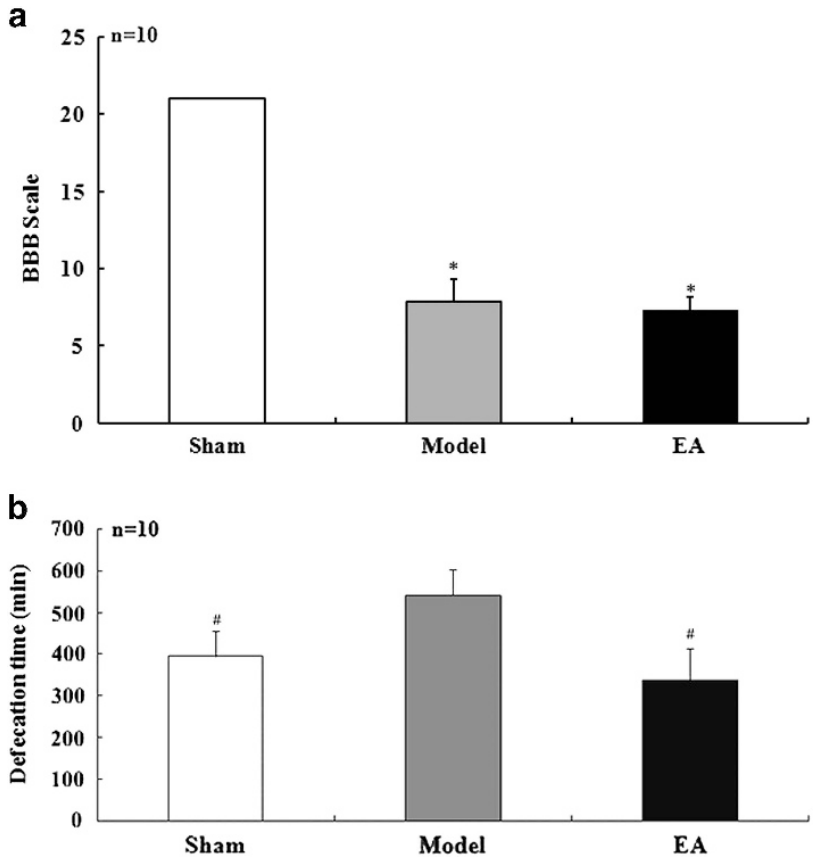

Figure $2 \mathrm{BBB}$ score and defecation time in the rats of the three study groups. (a) BBB score and (b) defecation time were measured at the 15 day after modeling. The results are expressed as the mean \pm s.e. ${ }^{*} P<0.01$ compared with the sham group. ${ }^{\#} P<0.01$ compared with the model group. $E A$, electroacupuncture.

SCI. All the 20 rats were divided randomly into the model group $(n=10)$ and the EA group $(n=10)$. At the 15 th day after modeling, $\mathrm{BBB}$ scores in the model group $(21 \pm 0)$ and the EA group $(7.35 \pm 0.82)$ were significantly lower than the sham group $(7.85 \pm 1.45, P<0.01$ for both, Figure $2 \mathrm{a})$.

\section{EA shortened the defecation time of SCI rats}

The defecation time (time from the administration of activated carbon to the evacuation of the first black stool) was shortest $(338.60 \pm 75.44 \mathrm{~min})$ in the EA group and longest $(541.20 \pm 61.79 \mathrm{~min})$ in the model group (Figure $2 \mathrm{~b})$. The defecation time in the sham group was $395.40 \pm 60.15 \mathrm{~min}$. The defecation time was significantly shorter in the sham and EA groups than in the model group $(P<0.01$ for both $)$.

\section{nNOS-immunoreactive cell number decreased after EA}

On immunohistochemical analysis in the sham group, nNOSimmunoreactive cells were found to be localized to areas surrounding the myenteric plexus of the colon, and the staining was prominent in the cytoplasm of positively stained cells. More nNOS-immunoreactive cells and intense nNOS staining were observed in the model group, compared with the sham group (average optical density: $0.76 \pm 0.04$ vs $0.48 \pm 0.06, P<0.01)$. Fewer nNOS-immunoreactive cells and less intense nNOS staining were observed in the EA group than in the model group (average optical density: $0.54 \pm 0.06$ vs $0.76 \pm 0.04$, $P<0.01$, Figure 3).

\section{nNOS mRNA and protein expression decreased after EA}

We found that nNOS mRNA expression in colon tissue was significantly higher in the model group than in the sham group $(0.004 \pm 0.001$ vs $0.001 \pm 0.0003 ; P<0.05)$ and significantly lower in 

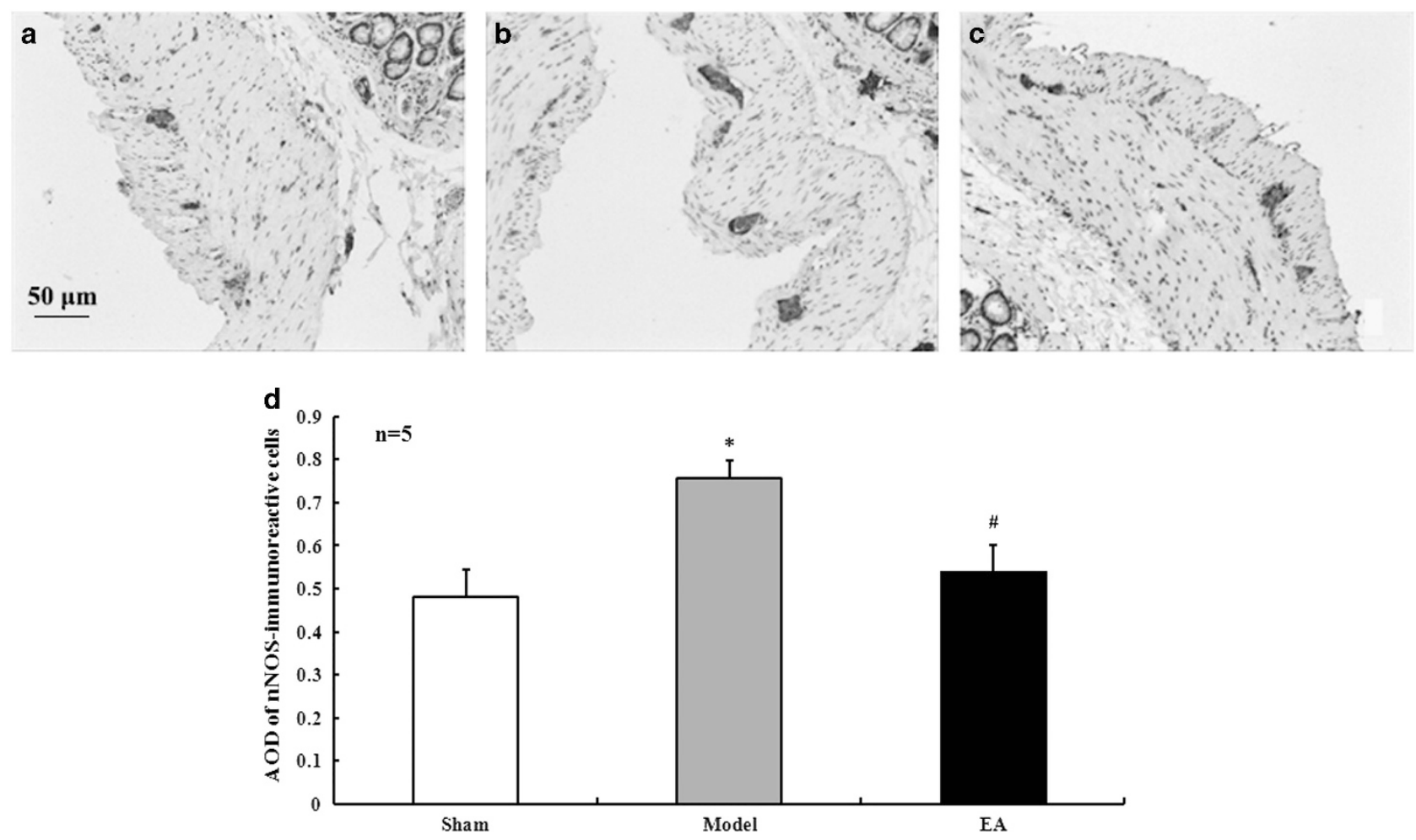

Figure $3 \mathrm{Immunohistochemical} \mathrm{analysis} \mathrm{of} \mathrm{neuronal} \mathrm{nitric} \mathrm{oxide} \mathrm{synthase} \mathrm{(nNOS)} \mathrm{in} \mathrm{the} \mathrm{myenteric} \mathrm{plexus} \mathrm{in} \mathrm{colon} \mathrm{tissue} \mathrm{samples.} \mathrm{(a)} \mathrm{Sham} \mathrm{group;} \mathrm{(b)} \mathrm{Model}$ group and (c) EA group. The magnification is $\times 200$. Scale bar $=50 \mu \mathrm{m}$. The brown color indicates NOS-positive neurons. (d) Average optical density (AOD) of nNOS-immunoreactive cells. The animals survived for 15 days. ${ }^{*} P<0.01$ compared with the sham group. ${ }^{\#} P<0.01$ compared with the model group. A full color version of this figure is available at the Spinal Cord journal online.

the EA group than in the model group $(0.001 \pm 0.0006$ vs $0.004 \pm 0.001, P<0.05$, Figure 4a).

To substantiate the qualitative immunostaining findings, we determined the protein levels of nNOS in colon tissue by performing western blot analysis. The protein levels of nNOS were significantly higher in the model group than in the sham group $(0.28 \pm 0.10$ vs $0.04 \pm 0.02, P<0.01)$ and significantly lower in the EA group than in the model group $(0.06 \pm 0.03$ vs $0.28 \pm 0.10, P<0.01$, Figures $4 \mathrm{~b}$ and c), which is consistent with the results of immunohistochemistry and RT-qPCR.

\section{DISCUSSION}

Acupuncture is one of the most popular alternative therapies, and it has been used for thousands of years. EA is a common form of acupuncture in which an electric current is passed through acupuncture needles. ${ }^{19}$ The parameters of EA can be precisely characterized, and hence it is reproducible. Studies have shown that EA at ST36 at a specific frequency can improve functional gastrointestinal diseases such as functional dyspepsia ${ }^{20}$ and irritable bowel syndrome. ${ }^{21}$ ST36, the he-sea point of the Stomach Meridian of Foot-Yangming, is one of the most common points for EA. Clinical studies have demonstrated the efficacy of EA at ST36 for regulating the intestinal motility. ${ }^{22,23} \mathrm{On}$ the basis of the clinical effects, we want to explore the mechanism. One study has proposed that ST36 is the 'heterotopic point' for the distal colon. ${ }^{24}$ EA at ST36 stimulates colonic motility, possibly through the segmental reflex, which increases the activity of parasympathetic postganglionic neurons to release acetyl choline (Ach). Two other studies have shown that, in normal, freely moving, conscious rats, EA at ST36 can improve the contractility of the colon. ${ }^{25,26}$ One of these studies reported that the stimulatory effect was transmitted via a sacral parasympathetic efferent pathway, ${ }^{26}$ and the other suggested that it was mediated by the cholinergic pathway. ${ }^{25}$ However, thus far, the mechanism underlying the beneficial effects of EA at ST36 on colonic function remains controversial. Little effort has been made, particularly in pathological conditions.

Previous studies have identified the efficacy of somatic stimulation for patients with neurogenic bladder after SCI, ${ }^{27,28}$ and peripheral nerve stimulation may have effects on the central nervous system. ${ }^{29,30}$ In this study, we observed a significant increase in nNOS mRNA and protein expression in the rat colon after Th10 injury. This finding indicated that $\mathrm{nNOS}$ is an important factor in NBD secondary to traumatic SCI, and nNOS upregulation may facilitate the emergence of NBD following SCI. After EA treatment for 14 days, there was a marked decrease in nNOS mRNA and protein levels in the rat colon, with the nNOS mRNA and protein levels in the EA group nearly recovering to the levels in the sham (control) group. Furthermore, assessments of the functional outcomes showed that GI transit was significantly increased in the EA group compared with the model group, indicating that the EA therapy had ameliorated NBD, possibly via the downregulation of nNOS. Our results are consistent with another report on NOS expression after SCI. Hong et al. ${ }^{8}$ found that the expression of inducible NOS in gastric and small intestinal tissue was obviously enhanced in SCI rats, and EA at ST36 obviously downregulated inducible NOS expression.

In our study, immunohistochemical analyses showed that nNOS expression was localized to the myenteric plexus, which is part of the enteric nervous system (ENS). The ENS is an extensive intrinsic nervous system in the gastrointestinal tract. It can control intestinal functions even when completely separated from the central nervous system (CNS). ${ }^{31}$ The defecation function is regulated by both the CNS 



Figure 4 The expression of nNOS mRNA and nNOS protein. (a) Real-time PCR assays show that nNOS mRNA expression is higher in the spinal cord injury (SCI) rats (model group) than in the sham-operated rats $(P=0.039)$ and that electroacupuncture (EA) significantly decreased nNOS mRNA expression, compared with the expression in the model group $(P=0.049)$. $(\mathbf{b}, \mathbf{c})$ Western blot analysis shows that nNOS protein expression is higher in the $\mathrm{SCl}$ rats than in the sham-operated rats $(P=0.000)$ and that $\mathrm{EA}$ significantly decreased nNOS protein expression, compared with the expression in the model group $(P=0.000)$. Each bar represents the mean \pm s.e. ${ }^{*} P<0.05$ compared with the model group.

and ENS. In healthy individuals, the propulsive reflexes of the distal colon and rectum are regulated by central control centers, and when appropriate defecation is triggered by central commands that are relayed through the defecation center in the lumbosacral spinal cord. ${ }^{32}$ If the cortico-spinal connections to the defecation centers are severed by spinal injury, voluntary control of defecation will be lost. ${ }^{33}$ However, direct stimulation of the defecation center in the spinal cord can still cause coordinated emptying of the colon with the help of the ENS. ${ }^{34}$ Therefore, if the spinal defecation center remains intact after spinal injury, it can be stimulated to command the ENS pathways for bowel emptying. ${ }^{35} \mathrm{NO}$, the primary transmitter for enteric inhibitory motor neurons, is formed in the neurons by nNOS and can directly control colonic motility. ${ }^{36}$ In addition, it is known that colonic motility follows a rhythm, and current data suggest that the rhythms in colonic motility are regulated by both clock genes and nNOS. ${ }^{37,38}$ Hoogerwerf et al. ${ }^{38}$ found that, in nNOS knockout mice, both rhythmic changes in the colonic circular muscles in response to Ach and stool output were attenuated. This indicated that nNOS may have an important role in the regulation of Ach-mediated depolarization. This evidence further solidified the role of nNOS in modulating the rhythmic change of colonic motility. Change of nNOS expression may lead to a predominant inhibitory effect on colonic smooth muscle during the inactive phase while the inhibition attenuates during the active phase of colonic motor activity.

\section{CONCLUSION}

Our preliminary results suggest that an increase in nNOS concentration in the colon can affect the rhythmicity of colon contractions and induce or aggravate NBD in rats with SCI. EA at ST36 was beneficial for the treatment of $\mathrm{NBD}$, and its effects were realized by the downregulation of nNOS expression in the colon. Further study is needed to characterize the effect of nNOS inhibitor administration at different stages of SCI.

\section{DATA ARCHIVING}

There were no data to deposit.

\section{CONFLICT OF INTEREST}

The authors declare no conflict of interest.

\section{ACKNOWLEDGEMENTS}

This work was supported by the National Natural Science Foundation for Young Scientists of China (Grant NO.81202735), Jiangsu Innovation Program for Graduate Education (Grant NO.SJLX15_0448) and the Research Innovation Program for College Graduates of Jiangsu Province (Grant NO.CXZZ13_0617).

1 Lynch AC, Wong C, Anthony A, Dobbs BR, Frizelle FA. Bowel dysfunction following spinal cord injury: a description of bowel function in a spinal cord-injured population and comparison with age and gender matched controls. Spinal Cord 2000; 38 717-723.

2 DeVivo MJ, Vogel LC. Epidemiology of spinal cord injury in children and adolescents. J Spinal Cord Med 2004; 27: S4-10.

3 Noonan VK, Kopec JA, Zhang H, Dvorak MF. Impact of associated conditions resulting from spinal cord injury on health status and quality of life in people with traumatic central cord syndrome. Arch Phys Med Rehabil 2008; 89: 1074-1082.

4 Clinical practice guidelines: Neurogenic bowel management in adults with spinal cord injury. Spinal Cord Medicine Consortium. J Spinal Cord Med 1998; 21: 248-293.

5 Liu CW, Huang CC, Yang YH, Chen SC, Weng MC, Huang MH. Relationship between neurogenic bowel dysfunction and health-related quality of life in persons with spinal cord injury. J Rehabil Med 2009; 41: 35-40.

6 Bloemen-Vrencken JH, Post MW, Hendriks JM, De Reus EC, De Witte LP. Health problems of persons with spinal cord injury living in the Netherlands. Disabil Rehabil 2005; 27: 1381-1389.

7 Krassioukov A, Eng JJ, Claxton G, Sakakibara BM, Shum S. Neurogenic bowe management after spinal cord injury: a systematic review of the evidence. Spinal Cord 2010; 48: 718-733.

8 Hong L. Regulating function of electroacupuncture at Zusanli point in rats with gastrointestinal motility disorder after spinal cord injury. PhD Dissertation. Guangzhou University of Chinese Medicine, 2008.

9 Wong AM, Leong CP, Su TY, Yu SW, Tsai WC, Chen CP. Clinical trial of acupuncture for patients with spinal cord injuries. Am J Phys Med Rehabil 2003; 82: 21-27.

10 Liu Z, Wang W, Wu J, Zhou K, Liu B. Electroacupuncture improves bladder and bowel function in patients with traumatic spinal cord injury: results from a prospective observational study. Evid Based Complement Alternat Med 2013; 2013: 543174.

11 Bredt DS, Hwang PM, Snyder SH. Localization of nitric oxide synthase indicating a neural role for nitric oxide. Nature 1990; 347: 768-770.

12 Barbiers M, Timmermans JP, Scheuermann DW, Adriaensen D, Mayer B, De GroodtLasseel $\mathrm{MH}$. Nitric oxide synthase-containing neurons in the pig large intestine: topography, morphology, and viscerofugal projections. Microsc Res Tech 1994; 29: 72-78.

13 Singaram C, Sengupta A, Sweet MA, Sugarbaker DJ, Goyal RK. Nitrinergic and peptidergic innervation of the human oesophagus. Gut 1994; 35: 1690-1696.

14 Ward SM, Xue C, Sanders KM. Localization of nitric oxide synthase in canine ileocolonic and pyloric sphincters. Cell Tissue Res 1994; 275: 513-527.

15 Sharma H, Alm PRole of nitric oxide on the blood-brain and the spinal cord barriers. In: The Blood-Spinal Cord and Brain Barriers in Health and Disease. Elsevier Academic Press: San Diego, CA. 2004.

16 Wu WResponse of nitric oxide synthase to neuronal injury. In: Functional Neuroanatomy of the Nitric Oxide System. Elsevier: Amsterdam, The Netherlands. 2000. 
17 Tian W, Zhang Y, Sun L, Wang ZM. Establishment and evaluations of the spinal cord injury model. Chin J Rehabil Theory Pract 2010; 16: 221-223.

18 Yang Y, Pu Y. Establishment and evaluations of the spinal cord injury model. Chin J Traumatol 2002; 18: 187-189.

19 Yang ES, Li PW, Nilius B, Li G. Ancient Chinese medicine and mechanistic evidence of acupuncture physiology. Pflugers Arch 2011; 462: 645-653.

20 Xu S, Hou X, Zha H, Gao Z, Zhang Y, Chen JD. Electroacupuncture accelerates solid gastric emptying and improves dyspeptic symptoms in patients with functional dyspepsia. Dig Dis Sci 2006; 51: 2154-2159.

21 Wu HG, Liu HR, Zhang ZA, Zhou EH, Wang XM, Jiang B et al. Electro-acupuncture relieves visceral sensitivity and decreases hypothalamic corticotropin-releasing hormone levels in a rat model of irritable bowel syndrome. Neurosci Lett 2009; 465: 235-237.

22 Niu CF, Wang ZP. Clinical research of electroacupuncture at acupoint ST36, ST37 and PC6 on recovery of intestinal peristalsis for patients after radical surgery of colorectal cancer. Chin J Gerontol 2008; 09: 924.

$23 \mathrm{Wu}$ ZL, Luo CL. Acupuncture at ST36 for postoperative recovery of gastrointestinal dysfunction: a systematic review and meta-analysis. Chin J Tradit Med Sci Technol 2015; 04: 471-473.

24 Yuxue Z, Changxiang C, Qingguang Q, Hui B, Junhong G, Xiaochun Y et al. Effect of manual acupuncture on bowel motility in normal kunming mouse. J Tradit Chin Med 2015; 35: 227-233.

25 Luo D, Liu S, Xie X, Hou X. Electroacupuncture at acupoint ST-36 promotes contractility of distal colon via a cholinergic pathway in conscious rats. Dig Dis Sci 2008; 53: 689-693.

26 Iwa M, Matsushima M, Nakade Y, Pappas TN, Fujimiya M, Takahashi T. Electroacupuncture at ST-36 accelerates colonic motility and transit in freely moving conscious rats. Am J Physiol Gastrointest Liver Physiol 2006; 290: G285-G292.

27 Qin J, Zhao YJ, Ren N, Tang JG, Ren DF, Shi XX et al. Significance of sacral nerve electro-acupuncture stimulation on the urinary function reconstruction of neurogenic bladder in the patients with cauda equine injury. Chin J Bone Joint 2014; 03: 665-669.

28 Zhou N, Huang $\mathrm{XL}$, Ding $\mathrm{XH}$. Functional magnetic stimulation for treating the neurogenic bladder in patients with spinal cord injury. Chin J Phys Med Rehabil 2003; 25: 732-735.

29 Ai K, Zhang H, Zhang YC, Bao QY, Li JX, Kuang JZ. Effect of electroacupuncture on urodynamics and expression of Caspase- 3 in bladder tissue in rats with neurogenic bladder after sacral spinal cord injury. Chin J Rehabil Theory Pract 2013; 19: 1104-1107.

30 Ai K, Zhang H, Kuang JZ, Zhang YC, Li JX, Bao QY. Effect of electroacupuncture on expression of nerve growth factor and TrkA in spinal cord tissue in rats with neurogenic bladder after sacral spinal cord injury. Chin J Rehabil Med 2014; 29: 948-950.

31 Furness JB. The Enteric Nervous System. Blackwell: Oxford. 2006.

32 Lynch AC, Frizelle FA. Colorectal motility and defecation after spinal cord injury in humans. Prog Brain Res 2006; 152: 335-343.

33 Lynch AC, Antony A, Dobbs BR, Frizelle FA. Bowel dysfunction following spinal cord injury. Spinal Cord 2001; 39: 193-203.

34 Shimizu Y, Chang EC, Shafton AD, Ferens DM, Sanger GJ, Witherington J et al. Evidence that stimulation of ghrelin receptors in the spinal cord initiates propulsive activity in the colon of the rat. J Physiol 2006; 576: 329-338.

35 Ferens DM, Habgood MD, Saunders NR, Tan YH, Brown DJ, Brock JA et al. Stimulation of defecation in spinal cord-injured rats by a centrally acting ghrelin receptor agonist. Spinal Cord 2011; 49: 1036-1041.

36 Furness JB. The enteric nervous system and neurogastroenterology. Nat Rev Gastroenterol Hepatol 2012; 9: 286-294.

37 Hoogerwerf WA. Role of clock genes in gastrointestinal motility. Am J Physiol Gastrointest Liver Physiol 2010; 299: G549-G555.

38 Hoogerwerf WA, Shahinian VB, Cornelissen G, Halberg F, Bostwick J, Timm J et al. Rhythmic changes in colonic motility are regulated by period genes. Am J Physiol Gastrointest Liver Physiol 2010; 298: G143-G150. 